\title{
Surface environment modification in Atlantic salmon sea-cages: effects on amoebic gill disease, salmon lice, growth and welfare
}

\author{
Daniel W. Wright ${ }^{1, *, * *}$, Lena Geitung ${ }^{2, * *}$, Egil Karlsbakk ${ }^{2}$, Lars H. Stien ${ }^{1}$, \\ Tim Dempster ${ }^{3}$, Tina Oldham ${ }^{4}$, Velimir Nola ${ }^{1}$, Frode Oppedal ${ }^{1}$ \\ ${ }^{1}$ Institute of Marine Research, Matre Research Station, 5984 Matredal, Norway \\ ${ }^{2}$ Department of Biology, University of Bergen, 5005 Bergen, Norway \\ ${ }^{3}$ Sustainable Aquaculture Laboratory - Temperate and Tropical, School of BioSciences, Parkville, VIC 3010, Australia \\ ${ }^{4}$ Institute of Marine and Antarctic Studies, University of Tasmania, Launceston, TAS 7250, Australia
}

\begin{abstract}
Surface environment modification is a potential parasite control strategy in Atlantic salmon sea-cage farming. For instance, a temporary low salinity surface layer in commercial-scale snorkel sea-cages has coincided with reduced amoebic gill disease (AGD) levels after an outbreak. We tested if a permanent freshwater (FW) surface layer in snorkel sea-cages would lower AGD and salmon lice levels of stock relative to snorkel cages with seawater (SW) only and standard production cages with no snorkels. Triplicate cages of each type with 2000 post-smolts were monitored in autumn to winter for $8 \mathrm{wk}$ and sampled 4 times. Lower proportions of individuals with elevated AGD-related gill scores were registered in SW and FW snorkel cages compared to standard cages; however, these proportions did not differ between SW and FW snorkel cages. Individuals positive for AGD-causing Paramoeba perurans were reduced by $65 \%$ in FW snorkel relative to standard cages, but values were similar between SW snorkel cages and other types. While total lice burdens were reduced by $38 \%$ in SW snorkel compared to standard cages, they were unchanged between FW snorkel and other cage types. Fish welfare and growth were unaffected by cage type. Surface activity was detected in all cages; however, more surface jumps were recorded in standard than snorkel cages. Overall, fish in FW snorkel cages appeared to reside too little in freshwater to consistently reduce AGD levels and salmon lice compared to SW snorkel cages. Further work should test behavioural and environmental manipulations aimed at increasing freshwater or low salinity surface layer use.
\end{abstract}

KEY WORDS: Aquaculture - Cage environment - Salmo salar - Lepeophtheirus salmonis · Paramoeba perurans $\cdot$ Parasite control

\section{INTRODUCTION}

Sea-cage Atlantic salmon Salmo salar farming produces more than $2.3 \times 10^{6} \mathrm{t} \mathrm{yr}^{-1}$ (FAO 2017). This new and constant availability of large numbers of hosts has led to an increased scale of salmon parasite outbreaks in many marine ecosystems (Nowak 2007). Outbreaks of the salmon louse Lepeophtheirus salmonis, and of the amoeba Paramoeba perurans re-

${ }^{*}$ Corresponding author: daniel.william.wright@imr.no

${ }^{* *}$ Joint first authors sponsible for amoebic gill disease (AGD) (Young et al. 2007, 2008b, Crosbie et al. 2012) are of particular concern to the industry (Murray et al. 2016). Salmon lice outbreaks are thought to harm wild salmonids (Krkošek et al. 2011, 2013) and, as a result, strict regulations limit salmon lice loads on farmed fish. Many farmers must treat their fish repeatedly against sea lice during a production cycle, leading to increased costs and considerable risk to fish welfare (Overton

(C) The authors 2018. Open Access under Creative Commons by Attribution Licence. Use, distribution and reproduction are unrestricted. Authors and original publication must be credited. 
et al. 2018). Norwegian authorities have also recently introduced the 'traffic light system', which limits allowable production volume in defined production zones according to the percentage of wild salmon in each production zone estimated to die due to salmon lice (Lovdata (2012)): $<10 \%=$ increased production (green), $10-30 \%=$ no change in production (yellow), $>30 \%=$ reduced production (red). In parallel, the expansion of AGD outbreaks to all major salmon farming regions has caused mass mortality events and a surge in AGD treatments (Shinn et al. 2015, Oldham et al. 2016). Innovating parasite controls to reduce both salmon lice and AGD could safeguard the ecological sustainability and future expansions of the salmon farming industry (Wright et al. 2017).

A range of chemotherapeutants can be used to treat salmon lice (organophosphates, emamectin benzoate, benzoyl ureas, hydrogen peroxide and pyrethroids) (Aaen et al. 2015), whilst AGD is currently treated with freshwater baths and hydrogen peroxide (Rodger 2014). Immersion in freshwater baths for 2 to $4 \mathrm{~h}$ removes freshwater-sensitive AGD-causing amoebae P. perurans from fish gills (Parsons et al. 2001, Clark et al. 2003, Rodger 2014). Unfortunately, short duration freshwater baths are unlikely to affect hostattached salmon lice which survive days to weeks in freshwater after developing past the first copepodid stage (Stone et al. 2002, Wright et al. 2016). In contrast, hydrogen peroxide use is rising rapidly (NIPH 2015, Murray 2016) due to its well known in-field efficacy against both salmon lice and AGD (Thomassen 1993, Adams et al. 2012). However, potential problematic effects on salmon welfare (Overton et al. 2018) and the evolution of chemical resistance against hydrogen peroxide (Helgesen et al. 2015, Helgesen et al. 2017) call into question the continued heavy reliance on this chemical. These factors are driving the development of chemical-free parasite controls. For salmon lice, these controls aim to prevent new lice from establishing themselves (fallowing, lice barrier skirt or snorkel cages, semi-enclosed cages, selective breeding of lice-resistant salmon) (Bron et al. 1993, Stien et al. 2012, Gharbi et al. 2015, Stien et al. 2016, Nilsen et al. 2017), or treat attached lice without chemicals (cleaner fish, laser, thermodelousing, water jets) (Bjordal 1990, Aaen et al. 2015). The challenge for these substitute controls will be to simultaneously diminish both salmon lice and AGD.

Snorkel sea-cages incorporate a deep net roof opening into a central tarpaulin-lined narrow net-tube (snorkel) to the surface in an otherwise standard cage (Stien et al. 2016). This impedes contact between salmon hosts and free-swimming infective larval stages of salmon lice which are positively phototactic and pressure sensitive, causing them to typically aggregate near the surface (Heuch 1995, Heuch et al. 1995). The snorkel allows salmon to swim up and gulp air at the surface to replenish their open swim bladder for buoyancy regulation (Fahlén 1971, Dempster et al. 2011). Snorkel cages can reduce salmon lice infestations relative to standard cages at research- and commercial scales (Stien et al. 2016, Wright et al. 2017), with their effectiveness increasing with increased depth of the snorkel (Oppedal et al. 2017). AGD may also be treated using this technology by adding a freshwater surface layer inside a tarpaulined lined tube in the snorkel space (Wright et al. 2017) that would remove P. perurans from gills if the fish expose themselves sufficiently to freshwater (Parsons et al. 2001, Clark et al. 2003, Roberts \& Powell 2003, Wright et al. 2016). Producing a temporary low salinity layer within the snorkels of commercial-scale cages has coincided with marked reductions in AGD levels after an outbreak, suggesting there is the potential for this technology to co-manage salmon lice and AGD (Wright et al. 2017). However, further testing is required to examine how variations of this surface environment modification, such as a permanent freshwater layer, affect AGD levels and to validate findings using standard production and seawaterfilled snorkel cages for comparison.

In this study, we tested if snorkel sea-cages with a constant freshwater layer reduced AGD levels relative to standard cages and seawater-filled snorkel cages. Even though it is well established that snorkel cages reduce salmon lice levels (Stien et al. 2016, Oppedal et al. 2017), we also examined cage type effects on salmon lice infestations. Introducing freshwater into snorkel cages holding salmon might affect salmon lice infestations by influencing the behaviour and physiology of the host (McCormick et al. 1998, Oppedal et al. 2011) or parasite, particularly at the freshwater-sensitive copepodid stage (Bricknell et al. 2006, Wright et al. 2016). Additionally, we investigated if growth, mortality and other welfare indicators differed between cage types. Environmental conditions were closely monitored at the farm as well as within each snorkel cage to explain observed patterns.

\section{MATERIALS AND METHODS}

\section{Study location and design}

Nine steel frame sea-cages $(12 \times 12 \mathrm{~m}$ square, $12 \mathrm{~m}$ deep) were used at the Institute of Marine Research farm facility in Austevoll, southwest Norway $\left(60^{\circ} \mathrm{N}\right)$. 
These consisted of 3 unmodified standard cages and 6 snorkel cages (snorkel dimensions were $3 \times 3$ m square, $4 \mathrm{~m}$ deep), with 3 snorkels filled with seawater pumped (135 $1 \mathrm{~min}^{-1}$ pump, Xylem Water Solutions) from $4 \mathrm{~m}$ depth (hereafter 'SW snorkel' cages) and 3 snorkels filled with mains ozone-treated freshwater containing no chlorine or fluoride ('FW snorkel' cages). The 2 treatments (SW and FW snorkels) were interspersed in a block design at the facility. We stocked each cage with 2000 post-smolt Atlantic salmon, naïve to both AGD and salmon lice exposure, in a randomized block order from 26 to 28 October 2016. Fish (AquaGen strain) were produced at the Institute of Marine Research tank facility in Matre as $0+$ out of season autumn smolts using standard protocols (e.g. Björnsson et al. 2000). Freshwater-filling of FW snorkels began after transfers were complete. Mean ( \pm SD) fish weight was $76 \pm 16 \mathrm{~g}$, which led to stocking densities of $0.09 \mathrm{~kg} \mathrm{~m}^{-3}$ in standard and snorkel cages. Fish were continuously fed small portions throughout daylight hours to excess with a commercial diet (3 mm Spirit Supreme pellets, Skretting) via an automated system that operated screw pellet dispensers which released feed centrally in standard cages and into a pipe where it was transported by pumping seawater or freshwater to the top of snorkels. Because fish were fed to excess, no food conversion ratio (FCR) data was recorded in this trial. Inconsistencies in the management of one replicate FW snorkel cage compared to others led to its removal from all analyses.

\section{Environmental depth profiles}

Daily depth profiles of salinity and temperature were recorded by an automatic profiling CTD buoy (APB5, SAIV) programmed to measure between 0 to $12 \mathrm{~m}$ starting at 12:00 h daily at a reference location near the centre of the farm facility. We supplemented these measurements with weekly depth profiles between 0 and $12 \mathrm{~m}$ of salinity, temperature and dissolved oxygen (DO) using a CTD (SD204, SAIV) at the reference location and within each snorkel cage, to record differences between cage environments. Weekly profiles began the week following stocking and once freshwater layer creation was complete. Profiles involved lowering the CTD at a rate of $1 \mathrm{~m}$ $\min ^{-1}$ to ensure the accuracy of oxygen recordings.

\section{Amoebic gill disease and salmon lice}

At fortnightly intervals, on 8-9 November (Time 1), 22-24 November (Time 2), 5-7 December (Time 3) and 20-21 December (Time 4), 20 fish from each cage were sampled. Fish were caught by ceasing feeding at least $24 \mathrm{~h}$ prior, lowering a hoop net and hand feeding to motivate surfacing of fish, followed by swift lifting of the hoop net. We subjected sampled fish to a lethal dose of anaesthetic (Finquel), then transferred them to seawater-filled trays for counts of all salmon lice stages (copepodid, chalimus I, chalimus II, preadult I, preadult II male, preadult II female, adult male, adult female and adult female with eggstrings). Counts of mobile stages in buckets holding the sampled fish were also included in the total counts. New lice at each sampling time were considered to be attached copepodid, chalimus I and chalimus II lice stages, which developed in $\leq 2 \mathrm{wk}$ at mean observed temperatures of $9^{\circ} \mathrm{C}$ in the trial (Stien et al. 2005). Next, AGD-related gill scoring (0-5, with 0 for no gill pathology and 1-5 for increasing severity of gill pathology, using lesion-covered gill surface area categories) was carried out on each of the 8 gill arches (Taylor et al. 2009). The AGD-related gill score given to an individual fish was based on the maximum score of its arches. At Time 3, when gill scores remained elevated, swabbing of the third right gill arch (a half turn on the front and a half turn on the back) was performed on 10 fish in each cage type. The swab was inserted into $1 \mathrm{ml}$ vials of RNAlater and stored at $4^{\circ} \mathrm{C}$ for $24 \mathrm{~h}$ and thereafter at $-18^{\circ} \mathrm{C}$ until PCR analysis for $P$. perurans detection (Pharmaq, Bergen, Norway). Analysed samples returned a cycle threshold (CT) value indicating $P$. perurans presence when below a cut-off of 30.0, with co-analysed control samples recording CT values above it. We created a $P$. perurans load index, where a CT value of 30.0 or greater had a $P$. perurans load of 0 , and lower CT values were transformed by subtracting 30 and reversing the sign of the resulting value (e.g. CT value of $28=P$. perurans load index of 2 ). AGD-related gill scores and $P$. perurans load were positively correlated based on individuals swabbed at Time 3 (Pearson's correlation, $t=2.8, \mathrm{p}<0.05$ ) providing support that gill scores resulted from AGDcausing $P$. perurans, as reported by others (e.g. Young et al. 2008a, Bridle et al. 2010).

\section{Growth, mortality and other welfare indicators}

At Time 4, sampled fish were measured for fork length $(\mathrm{cm})$ and weight $(\mathrm{g})$, condition factor $(\mathrm{K}) \mathrm{calcu}-$ lated as (weight $\times$ length ${ }^{-3}$ )/100 (Bolger \& Connolly 1989), and scores of individual welfare indicators (emaciation, vertebral deformity, sexual maturation, 
smoltification state, fin condition, skin condition, eye status, opercula, mouth jaw wound, upper jaw deformity, lower jaw deformity) contributing to the Semantic Welfare Index Model (SWIM) version 2.0. Lice and gill welfare indicators were not incorporated into overall SWIM scores. Numbers of mortalities in each cage were recorded from checks performed 3 times per week.

\section{Surface activity}

Beginning from the first sampling time, jumps and rolls were counted in a 5 min period within each cage on the same day at weekly intervals (Dempster et al. 2008). These numbers were recalculated to jumps per fish per day.

\section{Statistical analyses}

Proportions of AGD-related 'light plus' gill scores $(\geq 2$, with higher scores indicating increased gill pathology) used as a measure of AGD levels in salmon cages within industrial and research settings (Maynard et al. 2016) were compared. Generalised linear models with binomial error distributions, including treatment (standard, SW snorkel and FW snorkel) and cage (1-8) as factors, compared light plus gill scores at each time (using the glm function in $\mathrm{R}_{i}$ Crawley 2012). For each comparison, models incorporating treatment $\times$ cage, treatment + cage and treatment only were built and the simplest model was selected if no significant difference was identified between them via ANOVA tests (anova function in R). Arcsine-transformed proportions of fish with gills found to be $P$. perurans-positive in each cage were compared between treatments using $t$-tests (t.test function in R).

We assessed differences in new lice per fish (count data with overdispersion) between treatments at each time using generalised linear models with quasi-Poisson error distributions, which included treatment and cage as factors. As before, a simpler model was chosen from more complex ones if no difference was found from ANOVA tests between models. For an overall assessment of lice infestation levels that fish incurred during the study, we examined total lice numbers (including sessile and mobile stages) on sampled fish and in their bucket for each cage at the final sampling (Time 4). These total counts per cage were compared between treatments via $t$-tests.
At Time 4, when fish had experienced the different cage type treatments the longest, growth (based on weight), condition and square-root-transformed SWIM scores of sampled fish were compared using linear mixed-effect models, with treatment as a fixed effect and cage as a random effect (lme function in R). At Time 4, arcsine-transformed proportions of fish with fin (scores $\geq 3$ ), skin (scores $\geq 3$ ), eye (scores $\geq 2$ ) and cumulative mortalities in each cage were also compared between treatments via $t$-tests, which were also used to compare square-root-transformed jumps per fish per day in each cage, pooled from all weekly assessments, between treatments. Error distributions were checked for variance and normality (plot function in R). Results are presented as means $( \pm \mathrm{SE})$ and $95 \%$ confidence intervals (CIs).

\section{RESULTS}

\section{Environment}

Salinity remained high (>28.3) and non-stratified at the reference location (reflecting conditions in standard cages) and in the SW snorkel cages (Fig. 1, Table S1 in the Supplement at www.int-res.com/ articles/suppl/q010p255_supp.pdf). Thermal stratification with cooler upper layers occurred sporadically in both standard and SW snorkel cages, though was less severe in SW snorkels because snorkel water was constantly replenished with pumped warmer seawater from $4 \mathrm{~m}$ depth (Fig. 1, Table S1). In FW snorkel cages, a stable freshwater layer was continuously maintained (salinity $\leq 1$ in top $2 \mathrm{~m}$ ), of predominantly lower temperature than underlying water (Fig. 1, Table S1). As a result, temperatures between 0 and $1 \mathrm{~m}$ depth in FW snorkels were 2.6, 1.4, 0.7 and $1.4^{\circ} \mathrm{C}$ cooler than SW snorkels and 1.5, 1.2, 0.0 and $0.7^{\circ} \mathrm{C}$ cooler than in standard cages in the sampling interval periods before Times 1, 2, 3 and 4, respectively (Table S1). DO saturation remained stable between 77 and $85 \%$ for standard and SW snorkel cages, but levels were much higher (up to $148 \%$ ) in the freshwater surface layer of FW snorkel cages, particularly preceding Times 1 and 4 , due to the ozone treatment of freshwater (Table S1).

\section{Amoebic gill disease}

Soon after stocking at Time 1, AGD-related gill scores remained low and the proportion of fish with light plus scores $(\geq 2)$ were similar between cage 


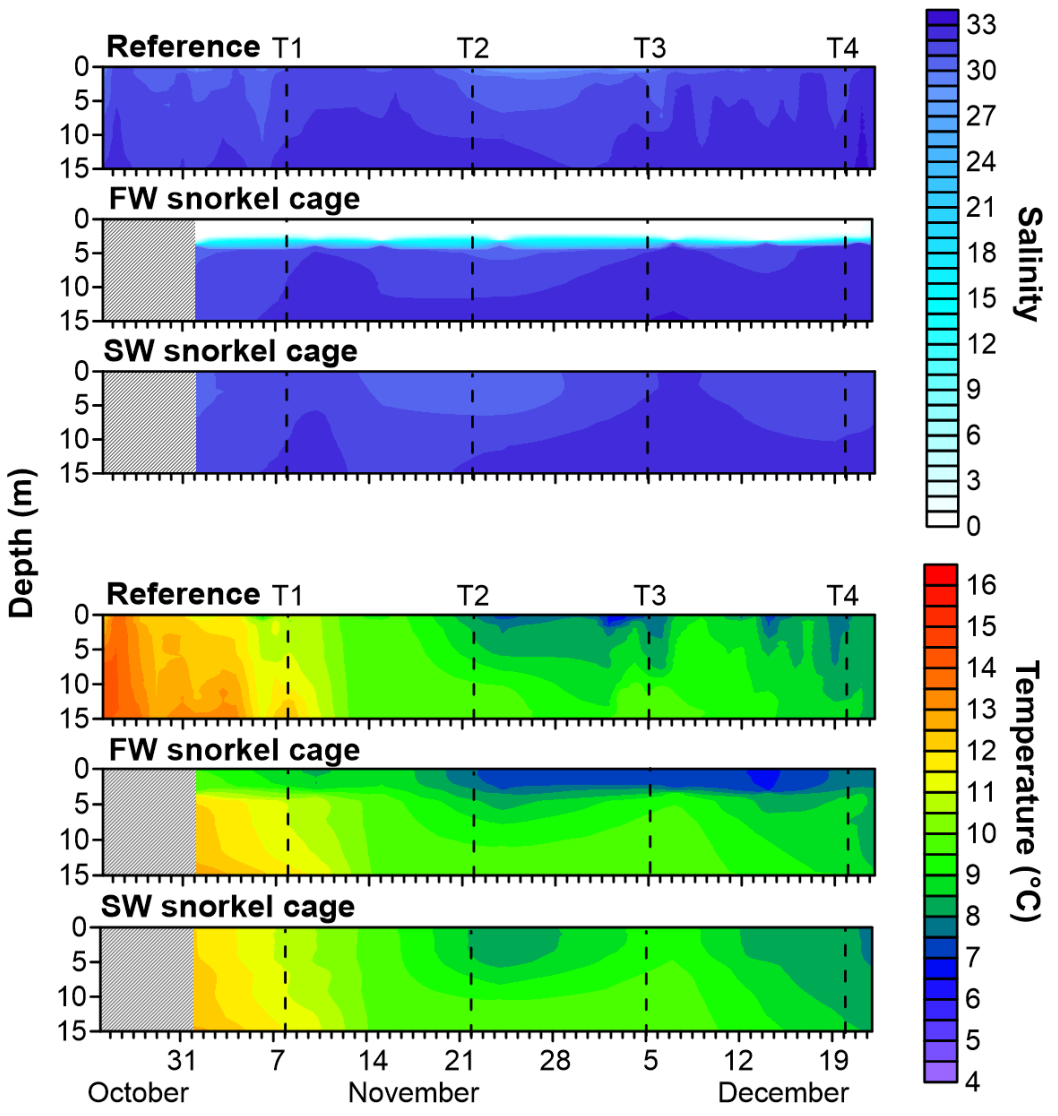

Fig. 1. Depth profiles over time of salinity (top) and temperature (bottom) in a study of the effects of surface environment modification on parasites in farmed Atlantic salmon Salmo salar in southwest Norway. Profiles were measured daily by an automatic profiling CTD buoy at a reference location, indicative of standard cage conditions and weekly using a CTD in snorkel cages filled with seawater (SW snorkel) or freshwater (FW snorkel). Measurements at the reference location were taken from 24 October 2016. Measurements in snorkel cages started on 1 November once freshwater layers were established, and the preceding period is shown as grey shading. Values are from a single FW and a single SW snorkel cage, with similar conditions observed in replicate cages. The 4 sampling times

(T1 to T4) are shown by dashed vertical lines types $(z \geq-1.7, \mathrm{p} \geq 0.1$; Fig. 2, Table S2). Gill scores increased thereafter and became highest in standard cages compared to SW snorkel cages at Times 2 and $3(z \geq$ $3.1, p<0.05)$, but not at Time $4(z=1.7, p=$ 0.1 ; Fig. 2, Table S2). These scores also remained lower in FW snorkel relative to standard cages at Times $2-4(z \leq-2.4, \mathrm{p}<$ 0.001; Fig. 2, Table S2). No differences were observed in gill scores between SW and FW snorkel fish at Times $2-4(z=0.01$ to $1.9, \mathrm{p}>0.06$; Fig. 2, Table S2). Cage and treatment $\times$ cage interactions were present for most comparisons between cage types at Times 2-4 (Fig. 2, Table S2). At Time 3, there was a $65 \%$ reduction in the proportion of fish with gills testing positive for Paramoeba perurans in FW snorkel (15\% of fish) compared to standard cages (43\% of fish) $(t=-4.7, \mathrm{p}<0.05)$, but not between SW snorkel cages (20\%) and other types ( $t \geq-2.6, \mathrm{p} \geq 0.1$; Fig. 2$)$.

\section{Salmon lice}

New lice (copepodid and chalimus stages) per fish were lower in SW snorkel relative to standard cages at Times 1 (means of 1.6 vs. 2.8) $(t=-4.3, \mathrm{p}<0.001), 2$ (means of 1.6 vs. 3.0) $(t=-5.3, \mathrm{p}<0.001)$ and 4 (means of 3.3 vs. 5.1) $(t=-2.4, \mathrm{p}<$ 0.05), but not at Time 3 (means of $1.6 \mathrm{vs}$. 2.7) $(t=-1.2, \mathrm{p}=0.9)$. At Time 3 , an interaction between treatment and cage occurred $(t=-2.0, \mathrm{p}<0.05$; Fig. 3$)$. FW
Fig. 2. Proportions of 'light plus amoebic gill disease (AGD)-related gill scores' (scores of $\geq 2$; see 'Materials and methods' for further details) for farmed Atlantic salmon in different cage treatments. Results are shown for each replicate $(\mathrm{n}=$ 3 replicates) standard (white bars), SW snorkel (grey bars) and FW snorkel cage (blue bars) at Times 1-4. See Fig. 1 legend for details of cage treatments and sampling times. Stippled bars indicate cages positioned closest to other AGDaffected cages at the farm and expected to be under increased infection pressure. Open circles at Time 3 denote proportions of Paramoeba perurans-positive fish from gill swab PCR analysis of 10 fish in each replicate cage. N/A indicates 1 FW snorkel cage discarded from analyses. ${ }^{*} \mathrm{p}<$ $0.05,{ }^{* * *} \mathrm{p}<0.001$
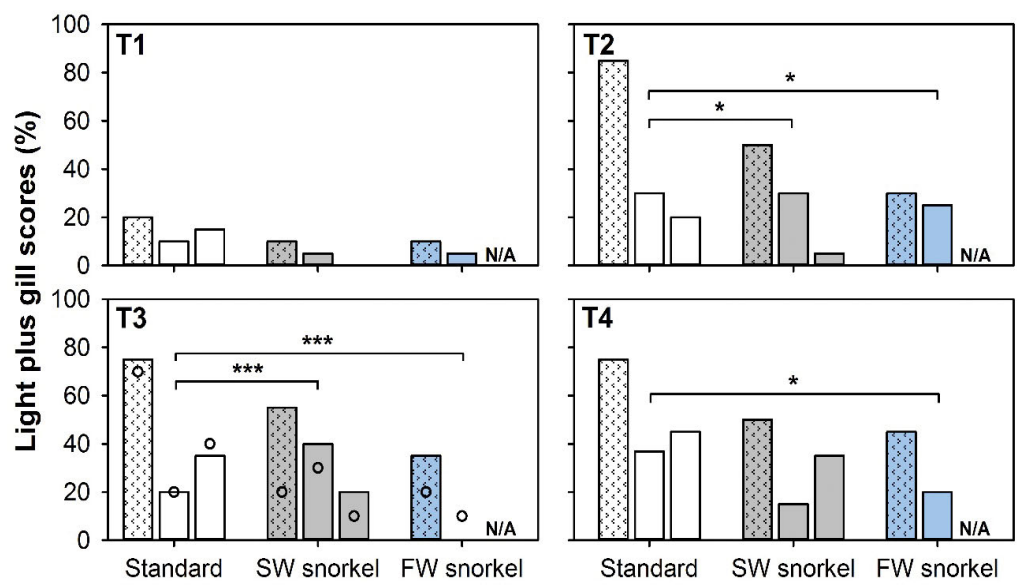

Cage type 


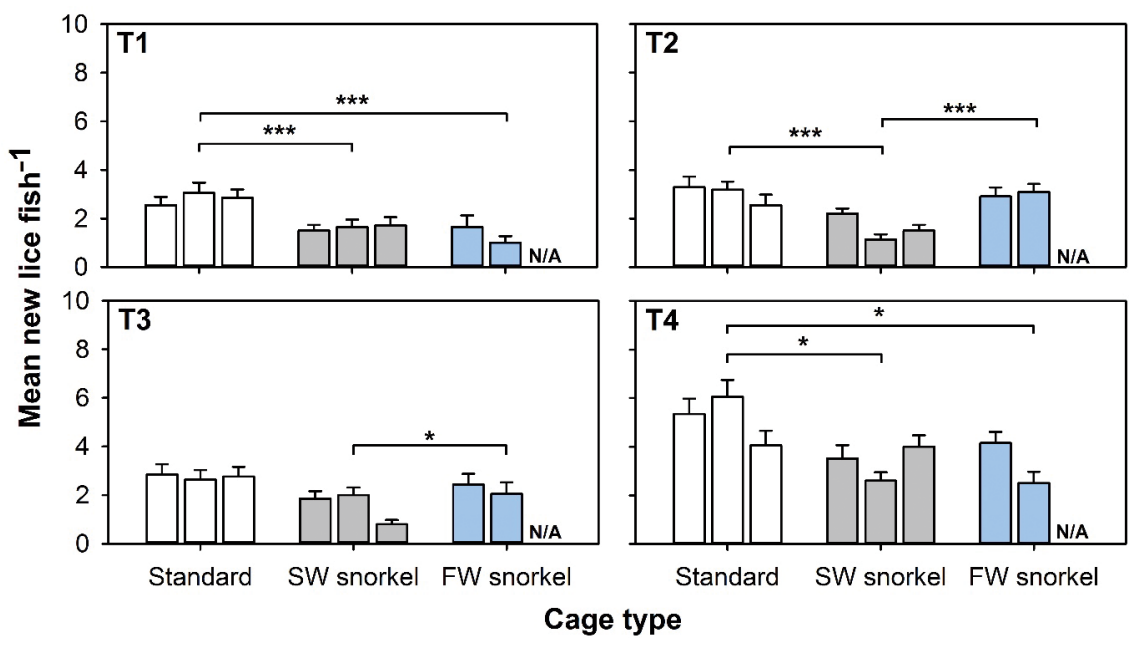

Fig. 3. Mean counts $( \pm \mathrm{SE})$ of new lice per fish (attached lice or copepodid, chalimus I and chalimus II lice stages) in farmed Atlantic salmon for each replicate standard (white bars), SW snorkel (grey bars) and FW snorkel cage (blue bars) at Times 1-4. See Fig. 1 legend for details of cage treatments and sampling times. N/A indicates $1 \mathrm{FW}$ snorkel cage discarded from analyses. ${ }^{*} \mathrm{p}<0.05,{ }^{* * *} \mathrm{p}<0.001$

snorkel fish also had fewer new lice than those in standard cages at Times 1 (means of 1.3 vs. 2.8 new lice per fish) $(t=-3.9, \mathrm{p}<0.001)$ and 4 (means of 3.3 vs. 5.1) $(t=-3.3, \mathrm{p}<0.05)$, although similar counts were observed at Times 2 (means of 3.0 vs. 3.0) $(t=$ $-0.1, \mathrm{p}>0.05)$ and 3 (means of 2.2 vs. 2.7) $(t=-1.3$, $\mathrm{p}<0.05$ ) (Fig. 3). Fish had fewer lice in cages with SW snorkels than with FW snorkels at Times $2(t=$ $-5.3, \mathrm{p}<0.001)$ and $3(t=-2.1, \mathrm{p}<0.05$; Fig. 3$)$. By Time 4 , when all lice stages were present in the 3 cage types, total lice per fish differed between standard and SW snorkel cages (means of 15.7 vs. 9.8; i.e. a $38 \%$ reduction) $(t=7.5, \mathrm{p}<0.05)$, but not between standard and FW snorkel cages (means of 15.7 vs. 12.6) $(t=0.9, \mathrm{p}=0.5)$ or $\mathrm{SW}$ and FW snorkel cages (means of 9.8 vs. 12.6) $(t=0.9, \mathrm{p}=0.5$; Fig. 4 ).

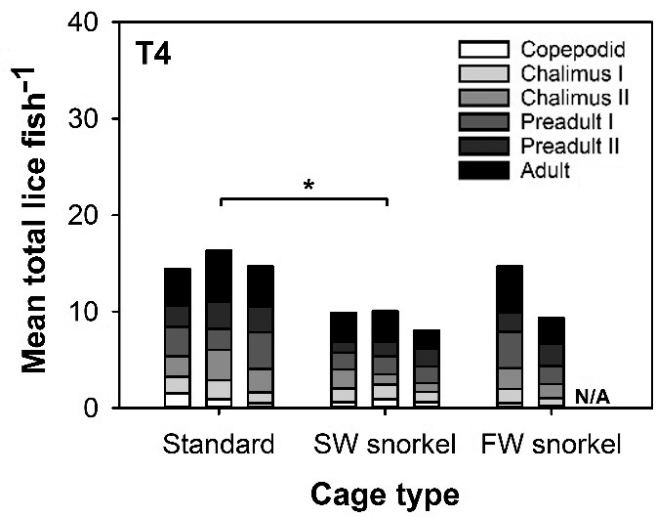

Fig. 4. Mean numbers of copepodids, chalimus I, chalimus II, preadult I, preadult II and adult lice per fish (later stages in increasingly darker shades from white to black) in farmed Atlantic salmon for each replicate standard, SW snorkel and FW snorkel cage at Time 4. See Fig. 1 legend for details of cage treatments and sampling times. N/A represents $1 \mathrm{FW}$ snorkel cage discarded from analyses. ${ }^{*} p<0.05$

\section{Growth, welfare and mortality}

At the last sampling point, there were no differences in the weight $\left(\chi^{2} \leq 2.2, \mathrm{p} \geq\right.$ $0.1)$ or condition factor $\left(\chi^{2} \leq 2.7, \mathrm{p} \geq 0.1\right)$ of sampled fish between cage types (Table 1). Adequate and comparable welfare scores of salmon were upheld in all cage types $\left(\chi^{2} \leq 3.5, p \geq 0.1\right.$; Table 1$)$. When individual welfare indicators were analysed separately, no differences in observed skin $(t \leq 3.2, \mathrm{p} \geq 0.1)$, fin $(t \geq-0.4$, $\mathrm{p} \geq 0.8$ ) or eye damage $(t \leq 2.5, \mathrm{p} \geq 0.1)$ existed between treatments. Mouth damage was only detected in standard cages (3.4\% of stock), and no fish were atypical for other welfare indicators (Table 1). $\mathrm{Cu}$ mulative mortalities were similar between cage types $(t \geq-0.6, \mathrm{p} \geq 0.6)$.
Table 1. Mean $( \pm \mathrm{SE})$ values for condition of farmed Atlantic salmon Salmo salar in southwest Norway held in standard cages, and in snorkel cages filled with seawater (SW snorkel) or freshwater (FW snorkel). Higher values for condition factor and overall Semantic Welfare Index Model (SWIM) score indicate better condition. Individual welfare indicator scores show proportions of individuals with high scores indicating deviance from the normal condition

\begin{tabular}{|lccc|}
\hline Parameter & Standard & SW snorkel & FW snorkel \\
\hline Mean weight (g) & $197.1 \pm 13.1$ & $177.3 \pm 4.8$ & $179.7 \pm 7.6$ \\
Mean condition factor & $1.15 \pm 0.02$ & $1.14 \pm 0.02$ & $1.19 \pm 0.01$ \\
Mean overall SWIM score & $0.92 \pm 0.01$ & $0.93 \pm 0.00$ & $0.93 \pm 0.00$ \\
Fin damage (scores $\geq 3$ ) & $64.4 \%$ & $65.0 \%$ & $62.5 \%$ \\
Skin damage (scores $\geq 3$ ) & $74.6 \%$ & $63.3 \%$ & $85.0 \%$ \\
Eye damage (scores $\geq 2$ ) & $84.7 \%$ & $58.3 \%$ & $40.0 \%$ \\
Mouth damage (scores $\geq 2$ ) & $3.4 \%$ & $0.0 \%$ & $0.0 \%$ \\
Emaciation (scores $\geq 2$ ) & $0.0 \%$ & $0.0 \%$ & $0.0 \%$ \\
Smoltification (scores $\geq 2)$ & $0.0 \%$ & $0.0 \%$ & $0.0 \%$ \\
Sexual maturation $($ scores $\geq 2$ ) & $0.0 \%$ & $0.0 \%$ & $0.0 \%$ \\
Vertebral deformity (scores $\geq 2)$ & $0.0 \%$ & $0.0 \%$ & $0.0 \%$ \\
Upper jaw deformity (scores $\geq 2$ ) & $0.0 \%$ & $0.0 \%$ & $0.0 \%$ \\
Lower jaw deformity (scores $\geq 2)$ & $0.0 \%$ & $0.0 \%$ & $0.0 \%$ \\
\hline
\end{tabular}




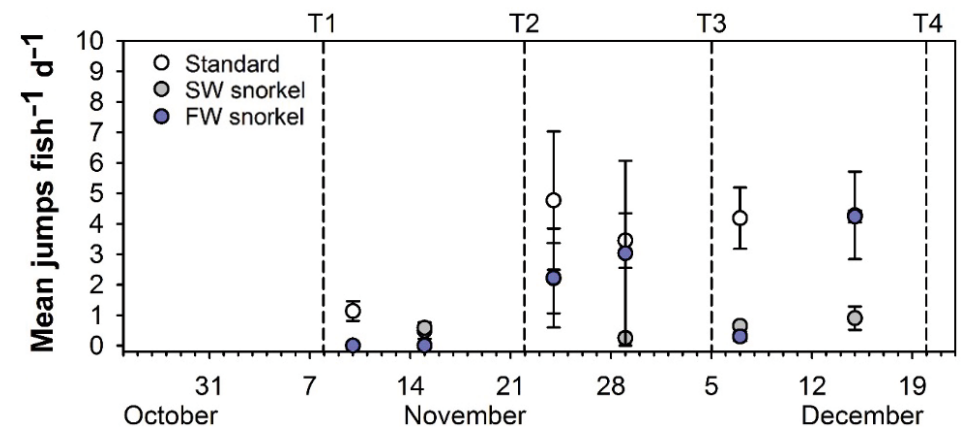

Fig. 5. Mean number $( \pm \mathrm{SE})$ of jumps per fish per day by farmed Atlantic salmon in standard (white circles), SW snorkel (grey circles) and FW snorkel cages (blue circles) at weekly assessments. Values for each cage type are aggregates from replicate cages ( $\mathrm{n}=3$ replicates). See Fig. 1 legend for details of cage treatments. The 4 sampling times (T1 to T4) are indicated by dashed lines

\section{Surface activity}

Surfacing by salmon was observed in all cage types and increased during the study, particularly after Time 2 (Fig. 5). Fish in standard cages performed more jumps per fish per day (mean of 3.0) than SW snorkel (mean of 0.8) and FW snorkel cages (mean of 1.3) ( $t \geq 2.8, \mathrm{p}<0.05$; Fig. 5). No differences in jump frequency were detected between SW and FW snorkel fish ( $t=0.04, \mathrm{p}=0.97$; Fig. 5).

\section{DISCUSSION}

SW and FW snorkel cages outperformed standard cages in terms of lowered AGD-related gill scores and reduced numbers of new salmon lice at some time points. All cage types had similar fish welfare and growth outcomes. However, we did not consistently detect reduced AGD and lice levels in FW snorkels compared to SW snorkels as initially predicted, with increases in new lice in FW compared to SW snorkel cages at certain time points. Daytime surfacing behaviour by salmon appeared unaffected between SW and FW snorkel cages. This suggests that while salmon frequently accessed the freshwater surface layer, their exposure durations were likely inadequate to alter AGD or salmon lice levels significantly below those in SW snorkel cages. Our results contrast with the AGD suppression observed in a commercial trial where freshwater was added to a snorkel to combat an AGD outbreak (Wright et al. 2017). There are several possible reasons for this, including differences in snorkel sizes that may affect salmon behaviours, and the multiple ways the freshwater layer water in the FW snorkel differed from the
SW snorkel other than salinity, including temperature and oxygen content.

\section{Effects of standard, SW and FW snorkels cages on AGD}

AGD-related gill scores, correlated with loads of AGD-causing Paramoeba perurans during the study, were often higher in standard cages, but similar between FW and SW snorkel cages. A higher proportion of P. perurans-positive fish were also found in standard compared to FW snorkel cages. Harvest-sized fish with high AGD-related gill scores were held in shallow cages within the research farm facility, measuring $\sim 30 \mathrm{~m}$ width $\times 120 \mathrm{~m}$ length. As swimming in the same depth and locality as AGD-affected individuals may increase AGD risk (Young et al. 2014), shallow swimming by fish in standard cages could have partially explained their higher AGD-related gill scores than snorkel fish. The lack of difference in AGD-related gill scores between FW and SW snorkel fish suggested that salmon mostly failed to enter freshwater sufficiently to decrease $P$. perurans populations on their gills (2 to $4 \mathrm{~h}$ freshwater baths are effective; Parsons et al. 2001, Clark et al. 2003, Rodger 2014).

\section{Effects of standard, SW and FW snorkel cages on salmon lice}

The lack of salmon lice reductions in FW snorkel cages indicated that the development of salmon lice on Atlantic salmon was unhindered by regular freshwater exposures during surface jumps (mean of 2.3 jumps per fish per day) and other possible times of residence. Thus, these periods were likely too short to eliminate freshwater-sensitive attached copepodids which takes 1 to $3 \mathrm{~h}$ (Wright et al. 2016). High salmon lice infestations of wild sea trout Salmo trutta are associated with entry into shallower brackish water or rivers, possibly for self-treatment against lice (Gjelland et al. 2014). Once completing their seaward out-migration, wild post-smolt Atlantic salmon also use less saline environments and this may also be a reaction to new salmon lice recruits (Mitamura et al. 2017). Despite the potential for Atlantic salmon to self-treat against salmon lice by moving from seawater to freshwater or low salinity environments, this did not occur under the conditions created in FW snorkel cages within the current trial. 
In some instances, FW snorkel cages increased new salmon lice infestations compared to SW cages. There are several possible reasons for this. Firstly, the freshwater exposures that salmon were subjected to may have removed mucus or induced stress, making them more susceptible to salmon lice infestations as has been documented for other external parasites such as Neobenedenia girellae skin flukes (Yamamoto et al. 2011). Reduced sheltering by fish inside snorkels filled with freshwater could also increase salmon lice infestations of FW compared to SW snorkel cages. While harvest-sized salmon have been found to position themselves almost exclusively below $4 \mathrm{~m}$ deep SW snorkels in identical cages in autumn (Stien et al. 2016), periodic post-smolt presence inside 4 to 16 m deep SW snorkels, inferred from low oxygen conditions, was detected by Oppedal et al. (2017). Therefore, greater fish residency inside SW snorkels may contribute to lice reduction effects typically seen in this cage type (see Oppedal et al. 2017). More work is needed to reveal differences in depth distribution of Atlantic salmon among standard, SW and FW snorkel cage types.

\section{Effects of standard, SW and FW snorkels cages on fish welfare and growth}

Fish welfare indicators and weights were similar between snorkel and standard cages, including where snorkels were filled with freshwater, confirming conclusions reached in previous snorkel cage investigations that use of this technology does not affect fish welfare (Oppedal et al. 2017, Wright et al. 2017). Snout damage, likely due to collisions with net roof and snorkel structures, has been observed in one research scale snorkel cage study (Stien et al. 2016) but we did not observe this negative effect here.

\section{FW in snorkels: contrasting results in commercial and experimental trials}

Commercial snorkels (10 m circle diameter $\times 10 \mathrm{~m}$ deep; volume $6448 \mathrm{~m}^{3}$; Wright et al. 2017) have a volume 179 times greater than our research snorkels. The greater volume within the snorkel may promote greater fish residence time. Greater numbers and densities of fish within larger snorkels may enable them to school in their standard circular swimming pattern $(\sim 500$ individuals are required to initiate schooling behaviour in 500-2000 $\mathrm{m}^{3}$ cages; Oppedal et al. 2011) and thus spend longer periods at a given depth. However, the smaller snorkels used in this study may have limited this behaviour and allowed only enough room for surfacing for swim-bladder refilling before returning to swimming in a school formation below the snorkel. Further, while feed entered the snorkel at the surface in both the commercial trial and this experiment, we observed that fish in the commercial trial entered the snorkel to take the feed, while in this trial they mostly waited until the feed had fallen below the snorkel depth. The restricted space in the smaller snorkel may have inhibited formation of the typical feeding aggregation at the surface and limited use by salmon of this layer.

In this trial, the freshwater layer was created by applying mains ozone-treated freshwater, whereas in the commercial trial, where far greater quantities were required, snorkels were filled with freshwater from a local river (Wright et al. 2017). These different methods of application and volumes of added freshwater created quite different outcomes in the surface layer's salinity, temperature and oxygen levels. Due to larger freshwater volumes and greater instability in a larger snorkel, salinity conditions achieved by filling snorkels with freshwater at a commercial scale (salinity of 4-5) were higher than the current study (always <1) (Wright et al. 2017). Salinity gradients also tended to be steeper in this research scale study (stable salinity between 0 and $2 \mathrm{~m}$ depth, then constantly increasing salinity between 2 and $4 \mathrm{~m}$ ) compared to the commercial-scale study (constantly increasing salinity throughout the snorkel) (Young et al. 2014). The higher salinity and its more gradual gradient may have provided a more attractive selftreatment space for Atlantic salmon to enter than an abrupt change to an almost completely fresh layer.

Freshwater filling with cooler temperature water, less preferred by salmon, has been typical in commercial- (Wright et al. 2017) and research-scale snorkels. At the commercial scale, surface water temperatures in individual snorkels filled with freshwater to varying degrees were 0.6 to $1.9^{\circ} \mathrm{C}$ cooler at the surface than reference conditions at one time (Wright et al. 2017), whereas in this study FW snorkels ranged from $1.5,1.2,0$ and $0.7^{\circ} \mathrm{C}$ cooler than reference conditions across 4 sampling points. Similarly lower surface temperatures in FW snorkels between these 2 studies point to these relatively small temperature differences being unimportant in freshwater layer use by salmon. However, a more attractive water temperature within the FW area should be tested to increase fish residence (Oppedal et al. 2011).

Oxygen supersaturation from ozone treatment occurred in the research scale FW snorkels used here, 
reaching levels (maximum 148\% DO saturation at Time 4) approaching those known to cause stress, gas bubble disease and behavioural and physiological changes in parr and pre-smolt Atlantic salmon (Brauner et al. 2000, Espmark \& Baeverfjord 2009, Espmark et al. 2010). In contrast, the low salinity layer in commercial snorkel cages filled from a local river had DO saturations of $<100 \%$ and was not ozone treated (Wright et al. 2017). Therefore, the oxygen supersaturation and, potentially, residual ozone in the surface freshwater layer in this study may have acted as a deterrent. However, limited information exists on the effects of oxygen supersaturation and residual ozone in post-smolt Atlantic salmon, so we are unable to gauge the extent of this possible effect in this trial.

Mean AGD-related gill scores in snorkel cages (mean gill scores in cages up to 1.9) in this study were lower than in the commercial trial, which experienced a major outbreak (mean gill scores in cages up to 2.8; Wright et al. 2017). Low stocking densities and holding caged fish at declining water temperatures in autumn to winter, rather than increasing temperatures in summer to autumn (elevated water temperature is associated with increased AGD incidence; Oldham et al. 2016), potentially contributed to the lower AGD-related gill scores and limited the detection of gill score differences between cage types. A follow-up investigation, where salmon in SW and FW snorkel cages experience a more severe AGD outbreak, would improve the detectability of AGD differences between these cage types.

\section{CONCLUSIONS}

In our autumn to winter study, a permanent freshwater surface layer maintained within snorkel lice barrier sea-cages holding Atlantic salmon did not affect their freshwater-sensitive ectoparasites, Paramoeba perurans and salmon lice. Salmon may have had limited contact time with the freshwater layer because of how they vertically positioned within snorkel cages or because they avoided the cool, super-oxygenated freshwater surface layer created to the extent that the parasites were not exposed sufficiently to the freshwater layer to produce an effect. Multiple changes to the freshwater surface layer to attract salmon to it are possible, including temporary night lighting strategies (Juell \& Fosseidengen 2004, Wright et al. 2015) and making surface waters warmer, less hyperoxic and more saline (Oppedal et al. 2011). These may intensify freshwater or low salinity layer use by salmon to the point where $P$. perurans and salmon lice are reliably diminished.

Acknowledgements. We thank Jan-Erik Fosseidengen and Tone Vågseth for technical support, along with Gunnar Didriksen, Sjur Åge Skår and others at Austevoll and Matre Research Stations for animal production and farm management. The trial was partly funded by Future Welfare (project 267800) within the Research Council of Norway, R\&D projects at Bremnes Seashore and the Norwegian Department of Fisheries and Coastal Affairs. The work was also funded by the Research Council of Norway (project number 256318/E40). The trial was conducted in accordance with the laws and regulations for experiments and procedures on live animals (FOTS ID: 9600/2016).

\section{LITERATURE CITED}

Aaen SM, Helgesen KO, Bakke MJ, Kaur K, Horsberg TE (2015) Drug resistance in sea lice: a threat to salmonid aquaculture. Trends Parasitol 31:72-81

Adams MB, Crosbie PBB, Nowak BF (2012) Preliminary success using hydrogen peroxide to treat Atlantic salmon, Salmo salar L., affected with experimentally induced amoebic gill disease (AGD). J Fish Dis 35:839-848

Bjordal $\AA$ (1990) Sea lice infestation of farmed salmon: possible use of cleaner fish as an alternative method for delousing. Can J Fish Aquat Sci 1761:85-89

Björnsson BT, Hemre GI, Bjørnevik M, Hansen T (2000) Photoperiod regulation of plasma growth hormone levels during induced smoltification of underyearling Atlantic salmon. Gen Comp Endocrinol 119:17-25

* Bolger T, Connolly PL (1989) The selection of suitable indices for the measurement and analysis of fish condition. J Fish Biol 34:171-182

*Bauner CJ, Seidelin M, Madsen SS, Jensen FB (2000) Effects of freshwater hyperoxia and hypercapnia and their influences on subsequent seawater transfer in Atlantic salmon (Salmo salar) smolts. Can J Fish Aquat Sci 57:2054-2064

* Bricknell IR, Dalesman SJ, O'Shea B, Pert CC, Luntz AJM (2006) Effect of environmental salinity on sea lice Lepeophtheirus salmonis settlement success. Dis Aquat Org 71:201-212

* Bridle AR, Crosbie PBB, Cadoret K, Nowak BF (2010) Rapid detection and quantification of Neoparamoeba perurans in the marine environment. Aquaculture 309:56-61

*Bon JE, Sommerville C, Wootten R, Rae GH (1993) Fallowing of marine Atlantic salmon, Salmo salar L, farms as a method for the control of sea lice, Lepeophtheirus salmonis (Krøyer, 1837). J Fish Dis 16:487-493

Clark G, Powell M, Nowak B (2003) Effects of commercial freshwater bathing on reinfection of Atlantic salmon, Salmo salar, with amoebic gill disease. Aquaculture 219: 135-142

Crawley MJ (2012) The R book. John Wiley \& Sons, London * Crosbie PBB, Bridle AR, Cadoret K, Nowak BF (2012) In vitro cultured Neoparamoeba perurans causes amoebic gill disease in Atlantic salmon and fulfils Koch's postulates. Int J Parasitol 42:511-515

* Dempster T, Juell JE, Fosseidengen JE, Fredheim A, Lader P (2008) Behaviour and growth of Atlantic salmon (Salmo salar L.) subjected to short-term submergence in com- 
mercial scale sea-cages. Aquaculture 276:103-111

* Dempster T, Kristiansen TS, Korsøen ØJ, Fosseidengen JE, Oppedal F (2011) Technical note: modifying Atlantic salmon (Salmo salar) jumping behavior to facilitate innovation of parasitic sea lice control techniques. J Anim Sci 89:4281-4285

Espmark ÅM, Baeverfjord G (2009) Effects of hyperoxia on behavioural and physiological variables in farmed Atlantic salmon (Salmo salar) parr. Aquacult Int 17: 341-353

Espmark ÅM, Hjelde K, Baeverfjord G (2010) Development of gas bubble disease in juvenile Atlantic salmon exposed to water supersaturated with oxygen. Aquaculture 306:198-204

Fahlén G (1971) The functional morphology of the gas bladder of the genus Salmo. Acta Anat 78:161-184

FAO (2017) Global aquaculture production. Food and Agriculture Organization of the United Nations. www.fao. org/fishery/statistics/global-aquaculture-production/en. (accessed April 2017)

Gharbi K, Matthews L, Bron J, Roberts R, Tinch A, Stear M (2015) The control of sea lice in Atlantic salmon by selective breeding. J R Soc Interface 12:0574

Gjelland KØ, Serra-Llinares RM, Hedger RD, ArechavalaLopez P and others (2014) Effects of salmon lice infection on the behaviour of sea trout in the marine phase. Aquacult Environ Interact 5:221-233

* Helgesen KO, Romstad H, Aaen SM, Horsberg TE (2015) First report of reduced sensitivity towards hydrogen peroxide found in the salmon louse Lepeophtheirus salmonis in Norway. Aquacult Rep 1:37-42

*Helgesen KO, Bakke MJ, Kaur K, Horsberg TE (2017) Increased catalase activity - a possible resistance mechanism in hydrogen peroxide resistant salmon lice (Lepeophtheirus salmonis). Aquaculture 468:135-140

Heuch PA (1995) Experimental evidence for aggregation of salmon louse copepodids (Lepeophtheirus salmonis) in step salinity gradients. J Mar Biol Assoc UK 75: 927-939

*Heuch PA, Parsons A, Boxaspen K (1995) Diel vertical migration: a possible host-finding mechanism in salmon louse (Lepeophtheirus salmonis) copepodids? Can J Fish Aquat Sci 52:681-689

Juell JE, Fosseidengen JE (2004) Use of artificial light to control swimming depth and fish density of Atlantic salmon (Salmo salar) in production cages. Aquaculture 233:269-282

Krkošek M, Connors BM, Morton A, Lewis MA, Dill LM, Hilborn R (2011) Effects of parasites from salmon farms on productivity of wild salmon. Proc Natl Acad Sci USA 108:14700-14704

Krkošek M, Revie CW, Gargan PG, Skilbrei OT, Finstad B, Todd CD (2013) Impact of parasites on salmon recruitment in the Northeast Atlantic Ocean. Proc R Soc B 280: 20122359

Lovdata (2012) Regulations on combating salmon lice in aquaculture facilities (in Norwegian: Forskrift om bekjempelse av lakselus i akvakulturanlegg) http://lovdata.no/ dokument/SF/forskrift/2012-12-05-1140 (accessed May 2018)

Maynard BT, Taylor RS, Kube PD, Cook MT, Elliott NG (2016) Salmonid heterosis for resistance to amoebic gill disease (AGD). Aquaculture 451:106-112

McCormick SD, Hansen LP, Quinn TP, Saunders RL (1998) Movement, migration, and smolting of Atlantic salmon
(Salmo salar). Can J Fish Aquat Sci 55:77-92

* Mitamura H, Thorstad EB, Uglem I, Økland F (2017) In situ measurement of salinity during seaward migration of Atlantic salmon post-smolts using acoustic transmitters with data-storage capabilities and conventional acoustic transmitters. Anim Biotelem 5:5

Murray AG (2016) Increased frequency and changed methods in the treatment of sea lice (Lepeophtheirus salmonis) in Scottish salmon farms 2005-2011. Pest Manag Sci 72:322-326

* Murray AG, Wardeh M, McIntyre KM (2016) Using the Hindex to assess disease priorities for salmon aquaculture. Prev Vet Med 126:199-207

Nilsen A, Nielsen KV, Biering E, Bergheim A (2017) Effective protection against sea lice during the production of Atlantic salmon in floating enclosures. Aquaculture 466: $41-50$

NIPH (Norwegian Institute of Public Health) (2015) Consumption of delousing agents remains high. www.fhi.no/ $\mathrm{hn} /$ legemiddelbruk/fisk/forbruket-av-lakselusmidler-erfort/ (accessed May 2018) (in Norwegian)

Nowak BF (2007) Parasitic diseases in marine cage culture-an example of experimental evolution of parasites? Int J Parasitol 37:581-588

Oldham T, Rodger H, Nowak BF (2016) Incidence and distribution of amoebic gill disease (AGD) - an epidemiological review. Aquaculture 457:35-42

Oppedal F, Dempster T, Stien LH (2011) Environmental drivers of Atlantic salmon behaviour in sea-cages: a review. Aquaculture 311:1-18

Oppedal F, Samsing F, Dempster T, Wright DW, Bui S, Stien LH (2017) Sea lice infestation levels decrease with deeper 'snorkel' barriers in Atlantic salmon sea-cages. Pest Manag Sci 73:1935-1943

* Overton K, Samsing F, Oppedal F, Dalvin S, Stien LH, Dempster T (2018) The use and effects of hydrogen peroxide on salmon lice and post-smolt Atlantic salmon. Aquaculture 486:246-252

* Parsons H, Nowak B, Fisk D, Powell M (2001) Effectiveness of commercial freshwater bathing as a treatment against amoebic gill disease in Atlantic salmon. Aquaculture 195:205-210

Roberts SD, Powell MD (2003) Reduced total hardness of fresh water enhances the efficacy of bathing as a treatment for amoebic gill disease in Atlantic salmon, Salmo salar L. J Fish Dis 26:591-599

Rodger H (2014) Amoebic gill disease (AGD) in farmed salmon (Salmo salar) in Europe. Fish Vet J 14:16-26

* Shinn AP, Pratoomyot J, Bron JE, Paladini G, Brooker EE, Brooker AJ (2015) Economic costs of protistan and metazoan parasites to global mariculture. Parasitology 142: $196-270$

* Stien A, Bjørn PA, Heuch PA, Elston DA (2005) Population dynamics of salmon lice Lepeophtheirus salmonis on Atlantic salmon and sea trout. Mar Ecol Prog Ser 290: 263-275

Stien LH, Nilsson J, Hevrøy EM, Oppedal F, Kristiansen TS, Lien AM, Folkedal O (2012) Skirt around a salmon sea cage to reduce infestation of salmon lice resulted in low oxygen levels. Aquacult Eng 51:21-25

Stien LH, Dempster T, Bui S, Glaropoulos A, Fosseidengen JE, Wright DW, Oppedal F (2016) 'Snorkel' sea lice barrier technology reduces sea lice loads on harvest-sized Atlantic salmon with minimal welfare impacts. Aquaculture 458:29-37 
Stone J, Boyd S, Sommerville C, Rae GH (2002) An evaluation of freshwater bath treatments for the control of sea lice, Lepeophtheirus salmonis (Krøyer), infections in Atlantic salmon, Salmo salar L. J Fish Dis 25:371-373

Taylor RS, Muller WJ, Cook MT, Kube PD, Elliott NG (2009) Gill observations in Atlantic salmon (Salmo salar, L.) during repeated amoebic gill disease (AGD) field exposure and survival challenge. Aquaculture 290:1-8

Thomassen JM (1993) Hydrogen peroxide as a delousing agent for Atlantic salmon. In: Boxshall GA, Defaye D (eds) Pathogens of wild and farmed fish: sea lice. CRC Press, Boca Raton, FL, p 290-295

Wright DW, Glaropoulos A, Solstorm D, Stien LH, Oppedal F (2015) Atlantic salmon Salmo salar instantaneously follow vertical light movements in sea cages. Aquacult Environ Interact 7:61-65

Wright DW, Oppedal F, Dempster T (2016) Early-stage sea lice recruits on Atlantic salmon are freshwater sensitive. J Fish Dis 39:1179-1186

Wright DW, Stien LH, Dempster T, Vågseth T, Nola V, Fosseidengen JE, Oppedal F (2017) 'Snorkel' lice barrier technology reduced two co-occurring parasites, the salmon louse (Lepeophtheirus salmonis) and the amoe-

Editorial responsibility: Chris Noble,

Tromsø, Norway bic gill disease causing agent (Neoparamoeba perurans), in commercial salmon sea-cages. Prev Vet Med 140: 97-105

* Yamamoto S, Shirakashi S, Morimoto S, Ishimaru K, Murata O (2011) Efficacy of oral praziquantel treatment against the skin fluke infection of cultured chub mackerel, Scomber japonicus. Aquaculture 319:53-57

Y Young ND, Crosbie PBB, Adams MB, Nowak BF, Morrison RN (2007) Neoparamoeba perurans n. sp., an agent of amoebic gill disease of Atlantic salmon (Salmo salar). Int J Parasitol 37:1469-1481

* Young ND, Dyková I, Nowak BF, Morrison RN (2008a) Development of a diagnostic PCR to detect Neoparamoeba perurans, agent of amoebic gill disease. J Fish Dis 31:285-295

*Young ND, Dykova I, Snekvik K, Nowak BF, Morrison RN (2008b) Neoparamoeba perurans is a cosmopolitan aetiological agent of amoebic gill disease. Dis Aquat Org 78:217-223

Young ND, Dyková I, Crosbie PBB, Wolf M, Morrison RN, Bridle AR, Nowak BF (2014) Support for the coevolution of Neoparamoeba and their endosymbionts, Perkinsela amoebae-like organisms. Eur J Protistol 50:509-523

Submitted: October 10, 2017; Accepted: March 26, 2018

Proofs received from author(s): May 31, 2018 